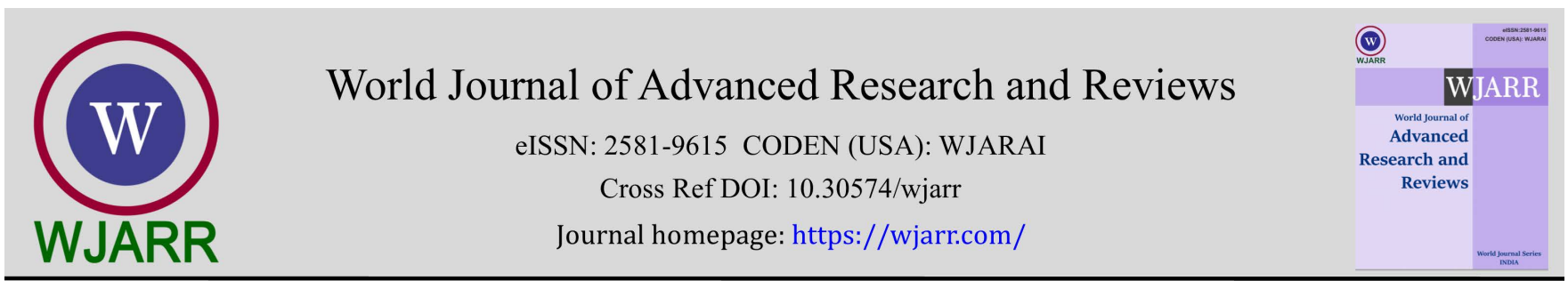

(RESEARCH ARTiClE)

\title{
Evaluation of the socio-economic impact of landcover / landuse changes in Owerri Municipal, Imo State, Nigeria using remote sensing and geographic information systems
}

Onyedikachim Ihuoma Njoku * and Joel Izuchukwu Igbokwe

Nnamdi Azikiwe University, Department of Surveying and Geoinformatics, Awka, Anambra State; Nigeria.

World Journal of Advanced Research and Reviews, 2021, 12(03), 175-180

Publication history: Received on 30 October 2021; revised on 06 December 2021; accepted on 08 December 2021

Article DOI: https://doi.org/10.30574/wjarr.2021.12.3.0665

\begin{abstract}
The study aimed at evaluating the socio-economic impact of land cover / landuse changes in Owerri Municipal, Imo State, Nigeria using remote sensing and GIS with a view to improving the quality of life and social development through its objectives; to identify the changes of the landcover and landuse pattern of the study area for a period of 30 years i.e. 1987 to 2002 to 2017, to evaluate the socio-economic and environmental impact of these changes and to predict future impact of landcover / landuse changes in the study area. The methodology adopted in this study involved sourcing of satellite data from United States Geological Survey (USGS) for the period of years under study, social survey in Owerri Municipal Area for socio-economic impact monitoring. ArcGIS 10.5 and QGIS 2.9 software were used for data processing, analysis and presentation. The study observed a significant increase in built-up area from 1987 (34\%) to 2017 (65\%), on the contrary, there was a noticeable decrease in the class of bare land (26\% to $12 \%$ ) and vegetation. (37\% to $15 \%$ ) followed by water body which kept fluctuating as result of rainfall. Rapid population growth triggered by rural urban migration coupled with hasty socio-economic development were the main drivers of these changes. Results showed that remote sensing and GIS approach are recommended for further studies as the tools are efficient for landcover/landuse mapping.
\end{abstract}

Keywords: Landcover/landuse mapping; Remote Sensing; GIS; Owerri Municipal; Socio-economics

\section{Introduction}

Landuse change is a popular concept and phenomenon in the existing literature of land, urbanisation, development control and related issues. Its resultant implications for physical fabric and socio-economic development and wellbeing of the affected populace are also issues of concern to policy makers and urban managers particularly in cities of developing countries like Nigeria. 'Ezeomedo and Igbokwe [4]'.

Observed environmental changes influenced with dramatic urban growth and their likely changes have led to adverse effects on the environment. 'Pongratz and Reick, Raddatz and Claussen [3]'. Landcover/landuse changes occur as a result of rapid rate of growth, development of our environment, agricultural activities which are carried out on land. 'Burney and Davis [2]'. The phenomenon is spreading throughout the country the country at a rapid rate with increased demand of alleniation on its rate of change overtime. The resultant effects of the changes lead to degradation, erosion, flooding, global warming, air pollution, etc. 'Adeniyi and Omojola [1]'.

\footnotetext{
${ }^{*}$ Corresponding author: Onyedikachim Ihuoma Njoku

Nnamdi Azikiwe University, Department of Surveying and Geoinformatics, Awka, Anambra State; Nigeria. 


\section{Material and methods}

\subsection{Study Area}

Owerri Municipal is a Local Government Area in Imo State. Its headquarters is in the city of Owerri. It has an area of 58 $\mathrm{km} 2$ and a population of 127,213 according to the 2006 census (NPC 2006). Owerri is bordered by the Otamiri River to the east and the Nworie River to the south. The study area lies between latitudes $5^{\circ} 26^{\prime} 40^{\prime \prime} \mathrm{N}$ to $5^{\circ} 31^{\prime} 20^{\prime \prime} \mathrm{N}$ and longitudes $7^{\circ} 0^{\prime} 20^{\prime \prime} \mathrm{E}$ to $7^{\circ} 4^{\prime} 20^{\prime \prime}$. See fig 1

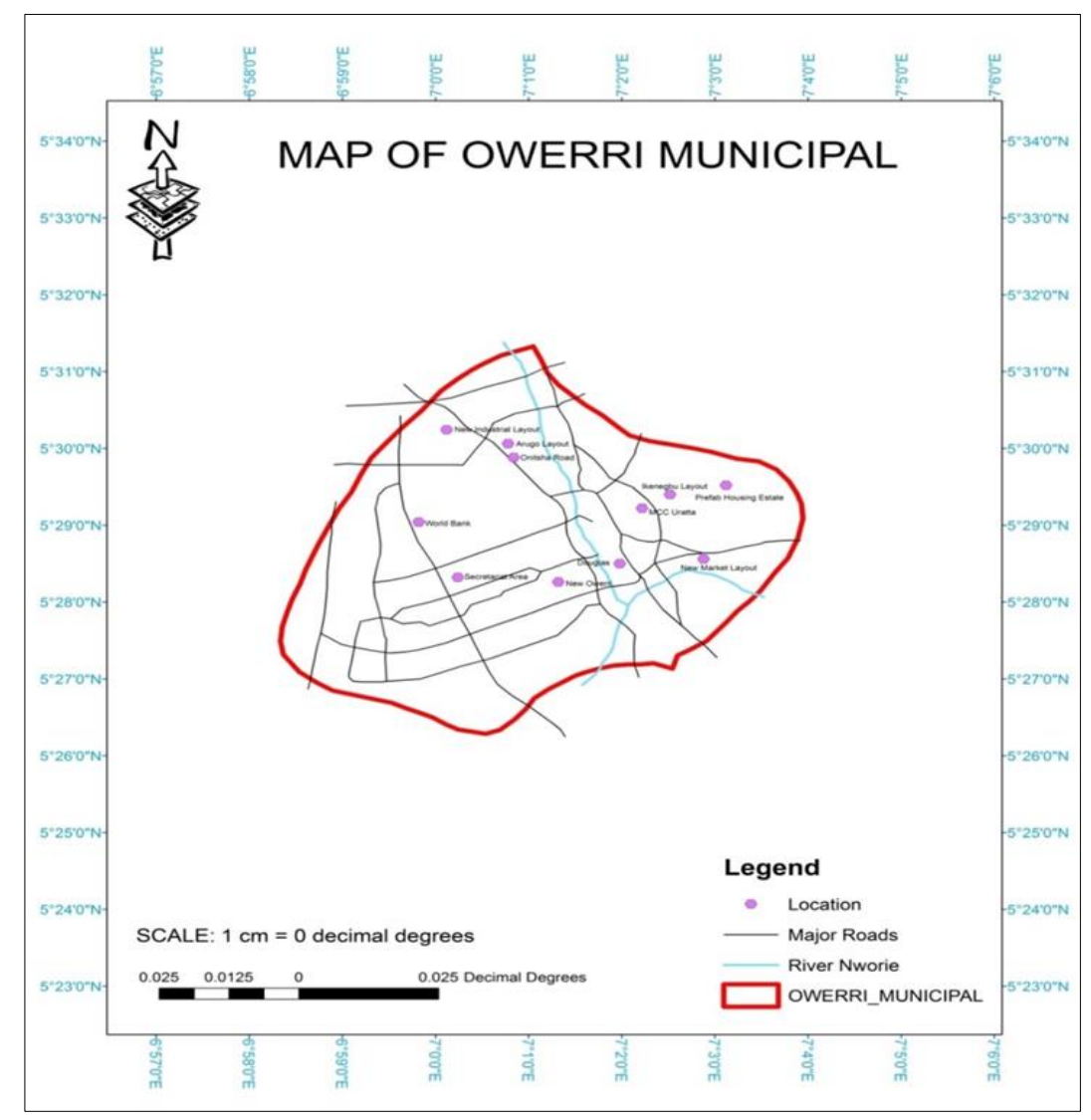

(Source: Ministry of Lands, Survey and Urban Planning, Imo State)

Figure 1 Map of Owerri Municipal (Study Area)

Owerri Municipal is found in the tropical rainforest region of Nigeria. It is according to the natural rainforest (Riparian forest and Low land forest Like most towns in Nigeria, it experiences two distinct climatic seasons; namely dry (October to March) and wet (April to September) seasons. A period of cold, dry, dusty winds known as "Harmattan" occurs from december to february annually.

\subsection{Materials}

The materials that were used to achieve the stated aim and objectives of the project are as follows; Landsat 5 multispectral scanner, Landsat 7 thematic mapper (TM) and Landsat 8 Operational Land Imager (OLI). These imageries were acquired from United State Geological Survey (USGS) at earthexplorer.usgs.gov with a spatial resolution of 30m, the digital administrative maps of Nigeria, Imo State and Owerri Municipal were sourced from Ministry of lands, housing and urban planning Imo State, questionnaire was developed for social survey, ArcGIS 10.5 version and QGIS 2.9 version software.

\subsection{Methods}

An unsupervised method of image classification was adopted for the image analysis. This method of classification in remote sensing basically generates clusters based on similar spectral characteristics inherent in the image. The steps for running an unsupervised classification on ArcGIS software: 
- Generate clusters: In this step, the software clusters pixels into a set number of classes. So, the first step is to assign the number of classes you want to generate. Also, you have to identify which bands you want to use.

- Assign classes: This step helps to identify each class from the Iso-clusters output. It selects colours for each class for instance; sets water as blue in each classification.

Two main methods of data analysis were adopted in this study are as follows;

- Calculation of the area in hectares of the resulting landuse/landcover types for each study year.

- Questionnaire Operations.

The comparison of the landuse/ landcover statistics assisted in identifying the percentage change and rate of change between 1987, 2002 and 2017. In achieving this, the first task was to develop a table showing the area in hectares and the percentage change for each year (1987, 2002 and 2017) measured against each land use/ land cover type. Percentage change was used to determine the trend of change for each land cover type

Table 1 Landuse/landcover distribution for 1987, 2002 \& 2017

\begin{tabular}{|l|l|c|c|c|c|c|c|}
\hline \multicolumn{7}{|c|}{ Landuse / landcover distribution for 1987, 2002 \& 2017 } \\
\hline & & \multicolumn{2}{c|}{$\mathbf{1 9 8 7}$} & \multicolumn{2}{c|}{$\mathbf{2 0 0 2}$} & \multicolumn{2}{c|}{$\mathbf{2 0 1 7}$} \\
\hline S/N & LU/LC & SQ.KMS & \% CHANGE & SQ.KMS & \% CHANGE & SQ.KMS & \% CHANGE \\
\hline 1 & $\begin{array}{l}\text { NWORIE- } \\
\text { RIVER }\end{array}$ & 1.228139 & 2.11869443 & 1.669704 & 2.88044965 & 1.051229 & 1.8135024 \\
\hline 2 & VEGETA-TION & 21.784069 & 37.5802621 & 18.253179 & 31.4890323 & 11.930656 & 20.5818839 \\
\hline 3 & BUILT UP & 19.7325 & 34.0410473 & 26.491799 & 45.7016892 & 37.722152 & 65.0754623 \\
\hline 4 & BARE LAND & 15.222075 & 26.2599962 & 11.552101 & 19.9288289 & 8.30115 & 12.5291514 \\
\hline TOTAL & & 57.966783 & 100 & 57.966783 & 100 & 57.966783 & 57.966783 \\
\hline
\end{tabular}

Also questionnaires were developed and shared to different groups of people in Owerri Municipal environs according to the sample size. The reason for this was to know the socio-economic impact of land cover/ land use changes on the people and their environments because as the Earth's population increase and national economies continue to move away from agriculture based systems, cities will grow and spread. The urbanisation often infringes upon viable agricultural or productive forest land neither of which can resist nor deflect the overwhelming momentum of urbanisation. City growth is an indicator of development and generally has a negative impact on the environmental health of a region.

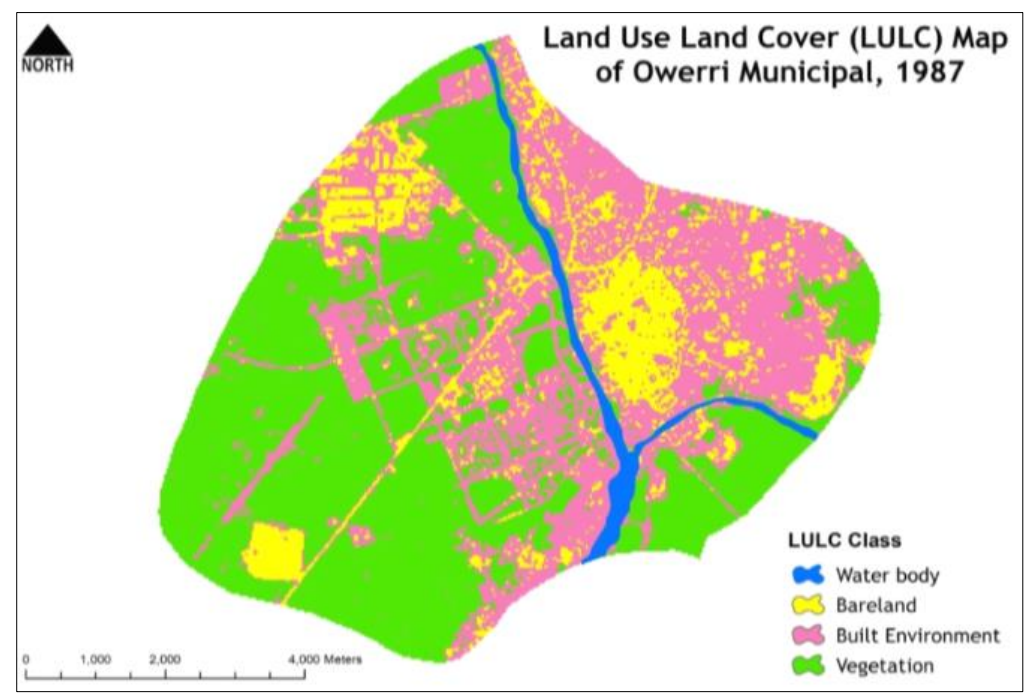

Figure 2 Landuse/landcover map of Owerri Municipal (1987) 


\section{Results and discussion}

\subsection{Classified Imagery of 1987}

Water body in 1987 occupied the least class. Also, bare land seemed to be minimal, occupying $26.25 \%$ of the total classes. Vegetation class recorded the highest composition occupying $37.58 \%$ of the total land size of the Description of Landsat Imagery.

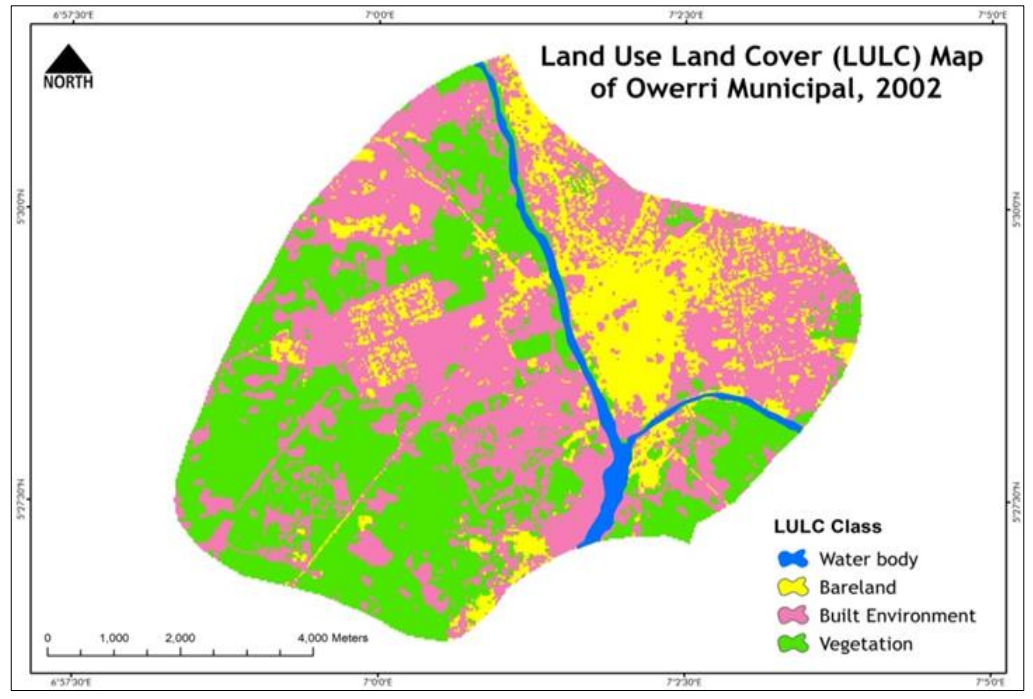

Figure 3 Landuse/landcover map of Owerri Municipal (2002)

\subsection{Classified Imagery of 2002}

Nworie River occupied the least class in 2002. Also the vegetation and bare land classes drastically dropped down in percentage, meaning there was an increase in some other land use class. Built-up area increased to $45.70 \%$, this increase showed that there was more building development in the municipal. However, the decrease in bare land showed there was either an increase in vegetation cover or building construction.

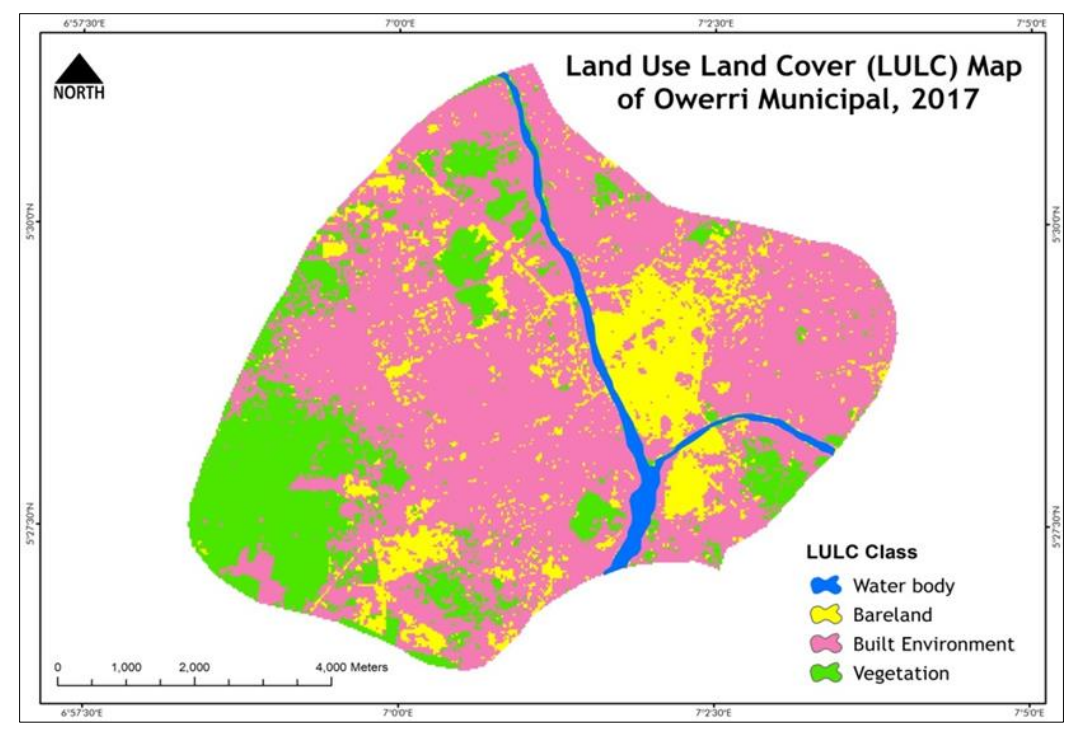

Figure 4 Landuse/landcover map of Owerri Municipal (2017)

\subsection{Classified Imageries of 2017}

Table 3.3 still showed there was a continuous increase in built-up area class i.e. $65.07 \%$, but every other class recorded a decrease. Water body class which was $1.81 \%$, vegetation recorded $20.58 \%$ which also showed that there was a 
decrease in agricultural activities like wise bare land which had a change of $12.52 \%$. It is shown in the land cover map below

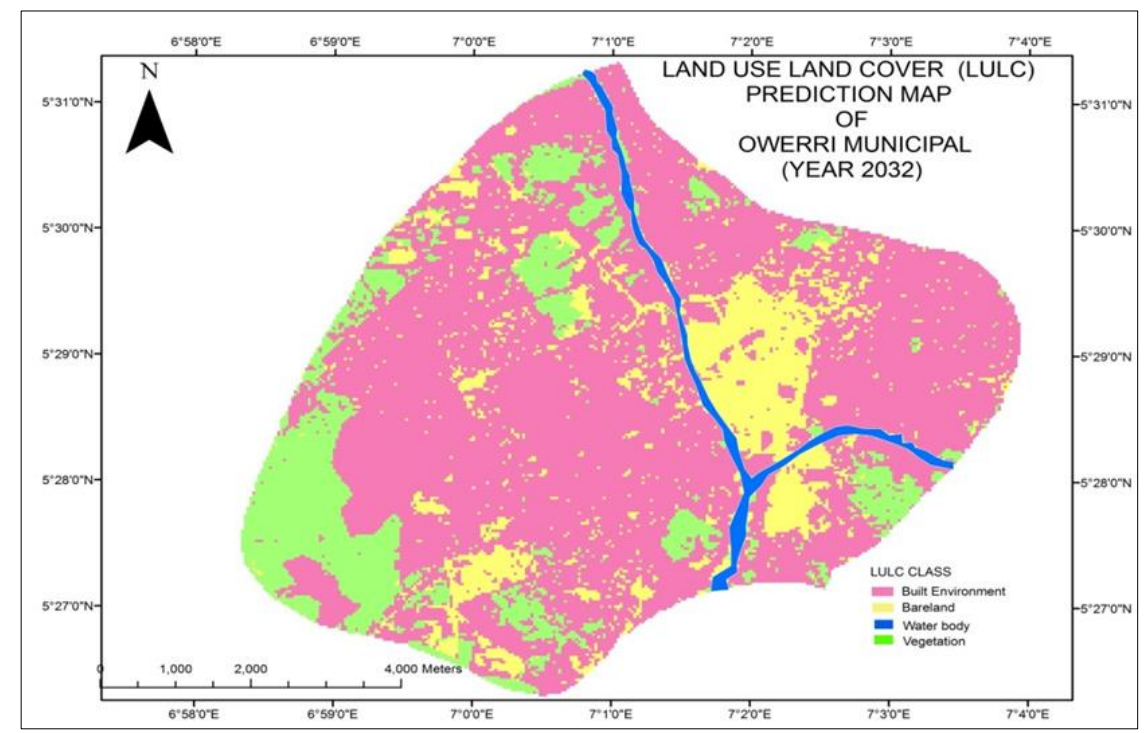

Figure 5 Landcover/landuse future prediction map (2032)

\subsection{Future prediction for the year 2032}

This prediction map confirms the assertion that built up area continued to increase throughout the study years. These findings are reflective of the current urbanization trend. The predicted trends of urban built slowly or rapidly taking over other important land types such as bare land and vegetation are similar to those reported by other urbanization studies in developing countries. If Owerri municipal is to avoid irreversible problems that are affecting many global cities, the municipality must shift from present business model to urgently adopt ecosystem based approach to urban development which is basically to plant fast growing trees.

\subsection{Socio-economic impact of landcover/landuse changes in Owerri Municipal}

Socio-economic factors are characteristics that define the quality of life in a society and this was where the essence of social survey came in. They influence the behaviours, attitudes, trends, tastes and lifestyles of individuals. Education, income and occupation are the main parameters of socio-economic status, according to the American Psychological Association. Other factors include; population/urbanisation, agriculture, etc.

Evaluating the socio-economic impact of landcover/ landuse changes from the questionnaire exercise, the key areas to look into are parameters which are measureable. To mention a few

- Population / Urbanisation refers to the population shift from rural to urban residency, the gradual increase in the proportion of living in urban areas and the ways in which each society adapts to this change. This shift can lead to increase in population and different kinds of crimes and the rate at which they occur. Following the responses gotten from the questionnaire exercise, $69.85 \%$ of respondents agreed that Urbanisation has an underlying influence on Land Cover and Land Use Changes, 17.97\% strongly agreed to this assertion while 12.17\% neither agreed nor disagreed to this factor. Since there is a higher percentage of people in the Municipality who agreed, this brings us to the conclusion that urban growth is one of the major factors of Land Cover Land Use Changes.

- Agriculture: Land cover and land-use patterns on Earth reflect the interaction of human activities and the natural environment. Human population growth together with competitive land use causes land scarcity, conversion of wild lands to agriculture and other uses. As we can see, the anthropogenic factor has an important impact on land use and land cover changes. Given this human influence, especially during the past 100 years, the recent period has been called the Anthropocene age. Human influence on the land and other natural resources is accelerating because of rapid population growth and increasing food requirements. The increasing agricultural intensity generates pressure not only on land resources but also across the whole environment. These factors make agriculture a top-priority sector for both economic and environmental policy. Impacts are commonly the result of multiple stressors. Agriculture exerts pressure on the environment that is both beneficial and harmful and can result in both positive and negative environmental impacts. The wide variation in farming systems and practices 
throughout the world, and differing environmental characteristics mean that the effects of agriculture on the environment arise at site-specific level but can have impacts at local to global level.

Effect of deforestation on landcover/ landuse changes: Vegetation loss within Owerri Municipal poses a lot of threat to natural habitats, there by affecting the local biodiversity of the landscape. The influence of human activities is altering the natural landscapes by changing the abundance and spatial pattern of these habitats (Harris and Miller, 1984). The increasing problem of the deforestation for timber and other forest products has eroded most of the original biodiversity over the past decades. Trees absorb carbon dioxide $\left(\mathrm{CO}_{2}\right)$ that humans release into the atmosphere through respiration. They use it to prepare their own food through photosynthesis and release oxygen $\left(\mathrm{O}_{2}\right)$ into the atmosphere. When there is an increase in deforestation (either burning or cutting down of forest), $\mathrm{CO}_{2}$ is released and its content in the atmosphere increases, which in turn increases the average global temperature of the earth's surface and causes global warming. $41.16 \%$ of respondents strongly agreed that deforestation has its negative impact on land cover and land use, $37.39 \%$ agreed while $4.34 \%$ strongly disagreed. This means that indeed, deforestation has a role to play in change of landcover and landuse because these places maybe converted to construction purpose to accommodate the increasing population.

\section{Conclusion}

The present study was an integrated approach of remote sensing and GIS for landuse and landcover change detection. The study site is a typical example of how rapidly resources, especially vegetation cover is disappearing in Owerri as a whole. The broad pattern of major landuse and cover changes are known with some confidence and the literature is rich in contending explanation for them. The aforementioned forces behind these changes require most attention. The research done support the conclusion that neither population nor poverty alone constitutes the sole and major underlying causes of landcover change but responses to economic opportunities by inhabitants, as mediated by institutional factors, drive land-cover changes. Study also showed that remote sensing and GIS are effective tools for simulating urban changes, which are useful for guiding urban planning and management. The findings of this study are useful to policy makers, urban planners, and citizens to adopt better environmental management practices including adaptation and mitigation strategies for the city and its surrounding areas.

\section{Compliance with ethical standards}

\section{Acknowledgments}

My profound gratitude goes to Prof. Joel Igbokwe and Dr. Esomchukwu Igbokwe for their great input into this paper. All Authors read and approved the paper.

\section{Disclosure of conflict of interest}

There is no conflict of interest regarding this research, authorship and publication of this paper.

\section{References}

[1] Adeniyi P, Omojola A. Landuse and landcover change evaluation in Sokoto-Rima Basin of North Western Nigeria Based on Archival of the Environment. African Association of Remote Sensing of the Environment (AARSE) in Geoinformation Technology Applications for Resources and Environmental Management in Africa. 1999; 143172.

[2] Burney JA, Davis SJ, Lobell DB. Greenhouse Gas Mitigation by Agricultural Intensification Proceedings of the National Academy Science. 2010; 12052-12057.

[3] Pongratz J, Reick CH, Raddatz T, Claussen M. Bio-Geophysical Versus Geo-Chemical Climate Response to Historical Anthropogenic Landcover Change. Geophysical Research Letters. 2010; 37.

[4] Ezeomedo IC, and Igbokwe JI. Mapping and Analysis of Landuse and Landcover for a Sustainable Development Using Medium Resolution Satellite Images and GIS. International Journal of Engineering and Management Sciences. Department of Surveying and Geoinformatics, NnamdiAzikiwe University, Awka, Nigeria. 2012; 513519. 